\title{
Energy Absorption of Nano-Reinforced and Sandwich Composites in Ballistic and Low-Velocity Punch-Shear
}

\author{
Brahmananda Pramanik, P. Raju Mantena* \\ Department of Mechanical Engineering, University of Mississippi, Oxford, USA. \\ Email: *'meprm@olemiss.edu
}

Received January $25^{\text {th }}, 2012$; revised February $24^{\text {th }}, 2012$; accepted March $9^{\text {th }}, 2012$

\begin{abstract}
This paper presents an investigation on energy absorption characteristics of nano-reinforced panels, laminated face sheets and sandwich composites in high velocity ballistic and low velocity punch-shear experiments. The vinyl ester panels were reinforced with 1.25 and 2.5 wt. percent nanoclay and exfoliated graphite platelets. Three different face sheets were manufactured with E-glass, Owens Corning HP ShieldStrand ${ }^{\mathbb{B}}$ glass and T-700 Carbon woven fabric in vinyl ester; and one with the E-glass and graphite platelets impregnated vinyl ester matrix. The sandwich composites were fabricated with balsa, PVC foam, 3-D fiber reinforced Tycor ${ }^{\circledR}$ and fire resistant fly-ash based Eco-Core ${ }^{\circledR}$ cores in between E-glass/vinyl ester face sheets. Ballistic tests were conducted according to NIJ level III using a universal receiver equipped with a barrel to launch 0.308 caliber M80 ball round projectile at about $890 \mathrm{~m} / \mathrm{s}$. Low velocity punch-shear tests were performed at around $3 \mathrm{~m} / \mathrm{s}$ according to ASTM D3763 Standard using a drop-weight impact test system. The tortuosity of the fractured surface in nanocomposite specimens has been investigated using digital microscope. In ballistic tests, the 3-D fiber reinforced Tycor ${ }^{\circledR}$ core provided the most resistance when projectile strikes at the web-flange interface region. The 2.5 wt. pct. graphite platelet reinforced nanocomposite, HP ShieldStrand ${ }^{\circledR}$ glass vinyl ester face sheets, and E-glass/Eco-Core ${ }^{\mathbb{R}}$ sandwich composite showed the best energy absorption under low velocity punch-shear.
\end{abstract}

Keywords: Energy Absorption; Tortuosity; Ballistic; Punch-Shear; Nanocomposites; Sandwich Composites

\section{Introduction}

This research is primarily focused on developing stronger, safer and more cost-effective structures for the new generation naval ships; especially nanoparticle reinforced glass/carbon polymeric based composites and structural sandwich composites for blast, shock and impact mitigation. These blast resistant structures must endure the high stresses produced by not only shocks and ballistic, but also low velocity impacts. Minimal damage, with high energy absorption and penetration resistance is desired.

Gama et al. [1,2] and Xiao et al. [3] performed quasistatic, ballistic and low velocity impact punch-shear tests to define the elastic and absorbed energies of composites as a function of penetration displacement. Shaker et al. [4] studied the failure mechanism of basket weave and 3-D braided Kevlar-fabric reinforced epoxy composites under low and high velocity impacts. Hosur et al. [5] carried out low velocity impact tests on quasi-isotropic CFRP composite laminates. Deka et al. [6] explained the multisite impact response of laminate composites. The ballistic and punch-shear response of nanoparticle reinforced

${ }^{*}$ Corresponding author. vinyl ester panels, laminated face sheets and sandwich composites has been investigated in the present work.

NIJ level III Standard [7] was adopted for the high velocity ballistic tests where a universal receiver equipped with a barrel was used to launch 0.308 caliber M80 ball round projectile at about $890 \mathrm{~m} / \mathrm{s}$. Dynatup 8250 dropweight impact test system was used for low velocity punch shear tests according to ASTM D3763 Standard [8]. Low velocity tests were performed on $101.6 \mathrm{~mm} \times$ $101.6 \mathrm{~mm}(4 " \times 4$ ") square panel specimens with fixed circular boundary condition and impacted by a hemispherical-head plunger with added mass. The impact load, displacement, energy plots and visual inspection of the post damaged specimen described the punch shear response and failure characteristics of these composites.

\section{Material Description}

Five different DERAKANE 510A-40 vinyl ester thermoset nanocomposite panels, reinforced with 1.25 and 2.5 wt. percent Cloisite 30B nanoclay and exfoliated graphite $(\mathrm{xGnP})$ nanoplatelets, were considered for the nanocomposite specimen characterization. DERAKANE 510A-40 
is a brominated bisphenol-A based vinyl ester [9] consisting of 38 wt. pct. styrene, added with Butanone peroxide, N, N-Dimethylaniline, Cobalt Naphthenate and 2-4-Pentanedione additives to impart maximum fire retardance and chemical resistance with toughness. The samples were prepared (at Michigan State University) by dispersing of 510A-40 vinyl ester resin solution with different percentages of nanoclay or nanographite in a container for 4 hours, followed by multiple passes through a flow cell connected to a $100 \mathrm{~W}$ sonicator for sufficient exfoliation. The well-mixed vinyl ester resin solution with nanoclay or nanographite was poured into a mold, let stand for 30 minutes at room temperature and then was post cured at $80^{\circ} \mathrm{C}$ for 3 hours.

Four different woven fabric laminated composite face sheets were fabricated (at University of Alabama, Birmingham) with Dow Derakane 510A-40 brominated vinyl ester resin by the VARTM process. The base specimen is a five-ply E-glass woven fabric with laminate schedule $[(0 / 90) /(+45 /-45) /(0 / 90) /(+45 /-45) /(0 / 90)]$. The second face sheet was prepared with same laminate configuration, but with 2.0 wt. pct. xGnP- 15 exfoliated graphite platelets pre-mixed in the vinyl ester resin before fabrication. The third face sheet was made with fivelayers of Owens Corning high performance HP ShieldStrand $^{\circledR}$ glass fabric with similar laminate schedule and resin. The fourth face sheet was made with only three plies of FOE treated T-700 carbon fabric $[(0 / 90) /$ $(+45 /-45) /(0 / 90)]$ laminate schedule in same matrix. Here the number of plies was reduced from five to three to keep stiffness of this carbon fabric laminate consistent with the other glass fabric face sheets.

Six different types of sandwich composites fabricated with 2" thick Tycor ${ }^{\circledR}$ (an engineered 3-D fiber reinforced damage tolerant core from WebCore Technologies), poly-vinyl chloride (PVC) foam, balsa-wood and three types of fire-resistant Eco-Core ${ }^{\circledR}$ (fly-ash based core material mixed with chopped JM3 and OC2 glass-fibers) sandwiched in between the five-ply E-glass/vinyl ester face sheets were fabricated (at University of Alabama, Birmingham) using VARTM process.

Areal density is one of the important parameters used for comparing the blast resistance of different composites with respect to steel [10]. All specimens investigated are of lesser areal density than that of a $6.35 \mathrm{~mm}(0.25$ ") thick structural steel plate with $48.8 \mathrm{~kg} / \mathrm{m}^{2}\left(10 \mathrm{lb} / \mathrm{ft}^{2}\right)$ areal density (Table 1). The dynamic responses are reported here by normalizing the load and energy absorption data to their respective areal densities (NTAD).

\section{Experimentation}

The high velocity ballistic experiments were conducted

Table 1. Areal densities of nanocomposites, laminated face sheets and sandwich composites.

\begin{tabular}{|c|c|c|c|c|c|c|c|}
\hline & & \multicolumn{2}{|c|}{ Volume Density } & \multicolumn{2}{|c|}{ Areal Density } & \multicolumn{2}{|c|}{ Thickness } \\
\hline & & $\left(\mathrm{kg} / \mathrm{m}^{3}\right)$ & $\left(\mathrm{lb} / \mathrm{in}^{3}\right)$ & $\left(\mathrm{kg} / \mathrm{m}^{2}\right)$ & $\left(\mathrm{lb} / \mathrm{ft}^{2}\right)$ & $(\mathrm{mm})$ & (in) \\
\hline \multirow{5}{*}{ Nano-composites } & Pure vinyl ester & 1338 & 0.048 & 14.0 & 2.867 & 10.0 & 0.39 \\
\hline & 1.25 wt. pct. nanoclay & 1347 & 0.049 & 14.0 & 2.867 & 10.0 & 0.39 \\
\hline & 2.5 wt. pct. nanoclay & 1352 & 0.049 & 14.0 & 2.867 & 10.0 & 0.39 \\
\hline & 1.25 wt. pct. graphite & 1352 & 0.049 & 14.0 & 2.867 & 10.0 & 0.39 \\
\hline & 2.5 wt. pct. graphite & 1363 & 0.049 & 13.0 & 2.663 & 10.0 & 0.39 \\
\hline \multirow{4}{*}{ Laminated face sheets } & E-glass & 1875 & 0.068 & 6.10 & 1.258 & 3.30 & 0.13 \\
\hline & E-glass/xGnP & 1747 & 0.063 & 8.40 & 1.721 & 4.80 & 0.19 \\
\hline & HP-glass & 1833 & 0.066 & 5.50 & 1.123 & 3.00 & 0.12 \\
\hline & T-700 Carbon & 1398 & 0.051 & 2.20 & 0.449 & 1.60 & 0.06 \\
\hline \multirow{6}{*}{ Sandwiches } & E-glass/Tycor & 386 & 0.014 & 22.6 & 4.623 & 57.2 & 2.25 \\
\hline & E-glass/PVC & 360 & 0.013 & 20.4 & 4.187 & 57.2 & 2.25 \\
\hline & E-glass/Balsa & 471 & 0.017 & 27.1 & 5.556 & 57.2 & 2.25 \\
\hline & E-glass/Eco 0.0 wt. pct. & 637 & 0.023 & 36.8 & 7.540 & 57.2 & 2.25 \\
\hline & E-glass/Eco 4.5 wt. pct. CO2 & 664 & 0.024 & 37.8 & 7.738 & 57.2 & 2.25 \\
\hline & E-glass/Eco 4.5 wt. pct. JM3 & 664 & 0.024 & 38.3 & 7.837 & 57.2 & 2.25 \\
\hline \multicolumn{2}{|c|}{ Structural steel (for comparison) } & 7861 & 0.284 & 48.8 & 10.00 & 6.35 & 0.25 \\
\hline
\end{tabular}


in accordance to the National Institute of Justice (NIJ) Threat Level III (M80) Standard [7]. The test weapon with an unvented velocity test barrel was mounted in the Universal Receiver (Figure 1). The receiver was attached to a table with sufficient restraint to ensure accurate shooting of repetitively fired rounds. Manually-loaded bullets of 9.6 grams (147 grains), $7.62 \mathrm{~mm}$ (0.308") nominal diameter and $28.2 \mathrm{~mm}$ (1.11") length were covered with an electro-deposited copper jacket.

Five specific shot locations were marked on each of the sandwich composite panels, three of them were closely located to get the relative ballistic interaction for sequential shots. For the Tycor ${ }^{\circledR}$ sandwich panel two target marks were at the web-intersection and other three marks were at the foam core region, to characterize the responses from different regions of the 3D-stitched core sandwich. The infrared ballistic screens and the proof chronograph captured striking and residual velocities respectively to determine the energy absorption characteristics of the sandwich panels.

Low velocity punch-shear experiments were performed using Dynatup 8250 drop weight impact test system according to ASTM D3763 Standard [8]. The specimen clamp assembly (Figure 2) consists of parallel rigid steel plates with a $76.2 \mathrm{~mm}$ (3") diameter hole in the center. Sufficient clamping force was applied to prevent slippage

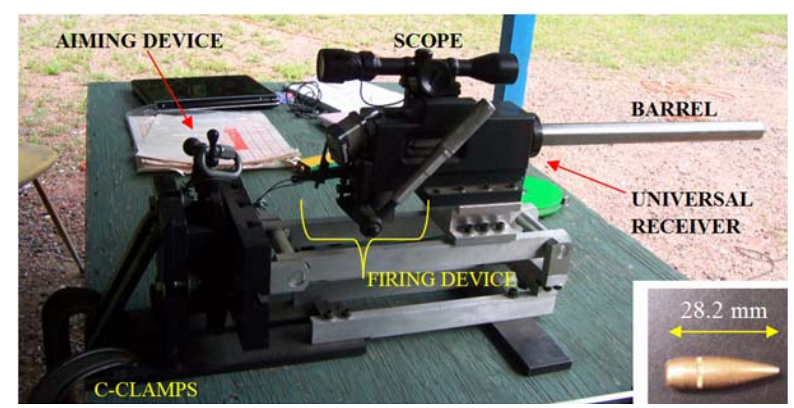

(a)

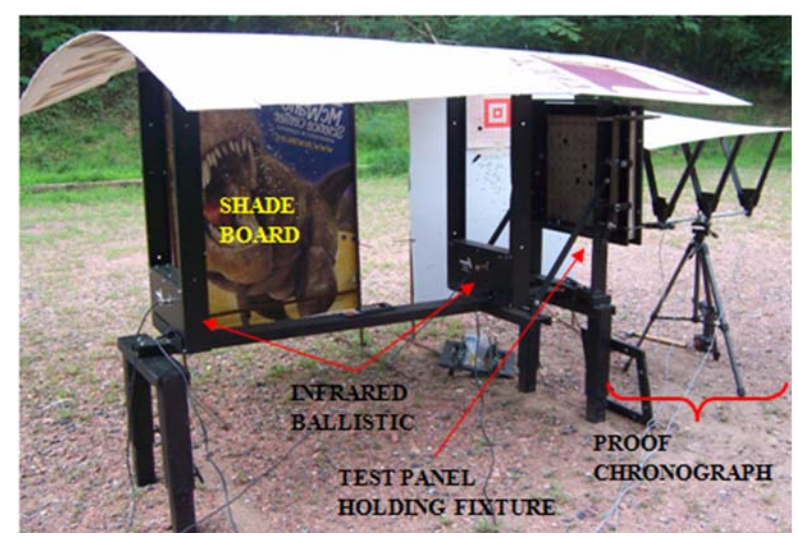

(b)

Figure 1. (a) Ballistic test weapon and projectile (inset); (b) Sandwich test specimen fixture and data acquisition system. of the specimen during impact. Plunger assembly consists of a $12.70 \mathrm{~mm}(0.5$ ") diameter steel rod of $50.8 \mathrm{~mm}$ (2") length with a hemispherical end of the same diameter positioned perpendicular to, and centered on the clamp hole.

Three samples from each type of nanoparticle reinforced vinyl ester panels, laminated face sheets and sandwich composites were tested under low velocity impact and the average data was considered for this investigation. A steel plunger was used for penetrating the specimens with the required impact energy and velocity. Impact drop weight and height were determined such that velocity slowdown at peak load point was less than $20 \%$ of impact point and the applied impact energy was at least three times the energy absorbed by the specimen at peak load [8]. This configuration provided about $38 \mathrm{~J}$ of impact energy and $3.6 \mathrm{~m} / \mathrm{s}$ impact velocity for the nanocomposites and about $185 \mathrm{~J}$ impact energy and $4 \mathrm{~m} / \mathrm{s}$ impact velocity for the laminated face sheets and sandwich composites.

\section{Results and Discussion}

High velocity ballistic damage was observed to have maximum destruction in through thickness cross-sectional view of Tycor ${ }^{\mathbb{R}}$ sandwich panel (Figure 3). The projectile, in this particular case, penetrated the sandwich panel at

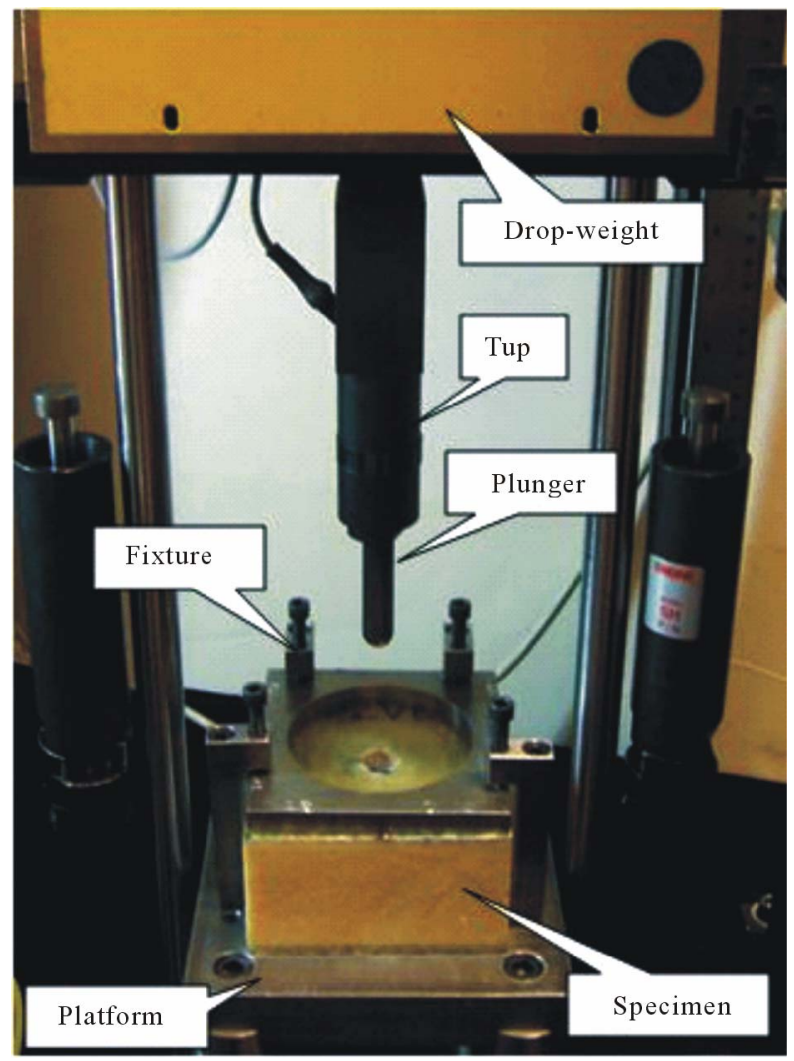

Figure 2. Low velocity punch-shear test system. 
web-intersection region. The projectile of only 0.308 " $(7.8 \mathrm{~mm})$ diameter penetrated the panel at about $890 \mathrm{~m} / \mathrm{s}$ velocity and created a inverted cone shaped damage through the thickness of the panel. It punctured the first face sheet leaving a small damage area on the skin. As in punch-shear testing, the web-intersection region of Tycor $^{\circledR}$ provided significant resistance to the projectile and deflected the penetration path randomly. The projectile with high kinetic energy ripped off the web fibers and foam pieces from their original locations. Large amount of foam pieces came out from the core system bursting out through the other end of face sheet, unweaving the fiber strands and with fiber breakage over a large area on the face skins. PVC, Balsa and Eco-Core ${ }^{\circledR}$ sandwiches showed similar type of face sheet penetration on impact side and back face side (Figure 3). The projectile with high kinetic energy punctured the face sheets without much delamination and permanent flexure. Only the fibers were ripped off from the path of projectile. The soft PVC, Balsa cores and brittle Eco-Core ${ }^{\circledR}$ did not offer significant resistance to the projectile. The transversely compressed PVC foam core was decompressed after ballistic penetration. Hence the projectile path was observed to be narrower than the size of projectile. Balsa sandwich allowed the projectile to penetrate through its balsa core with easy fiber-shear and transverse compaction, hence the penetration hole had the same diameter of the projectile. Eco-Core ${ }^{\circledR}$ fragments were dislodged from the cylindrical path of the projectile creating a cylindrical penetration hole of larger diameter.

A drop in the projectile velocities during complete penetration through each sandwich panel was observed. The kinetic energy (KE in J) absorbed by the target panel was calculated [4] using Equation (1):

$$
K E=\frac{1}{2} m\left(V_{S}-V_{R}\right)
$$

where, $m=$ projectile mass $(\mathrm{kg}), V_{S}=$ striking velocity $(\mathrm{m} / \mathrm{s})$ and $V_{R}=$ residual velocity $(\mathrm{m} / \mathrm{s})$.

Figure 4 illustrates the overall energy absorption capacity (normalized to areal density) of the sandwich panels. It shows that Tycor $^{\circledR}$ core sandwich panel absorbed maximum kinetic energy, whereas Balsa core and EcoCore ${ }^{\circledR}$ with 4.5 wt. pct. OC2 chopped glass fibers sandwich panel took the least. PVC foam core sandwich absorbed slightly higher energy than Balsa core sandwich but much less than the Tycor ${ }^{\circledR}$ core sandwich panel.

Residual velocities of the projectiles were not recorded for last three shots on PVC foam core panel and last four shots of Tycor ${ }^{\mathbb{B}}$ foam core panel, which would have given a better understanding of the material behavior. Debris and other small particles from the punctured foam masked these residual velocity measurements. This did not happen in case of Balsa wood core panels. It is to be
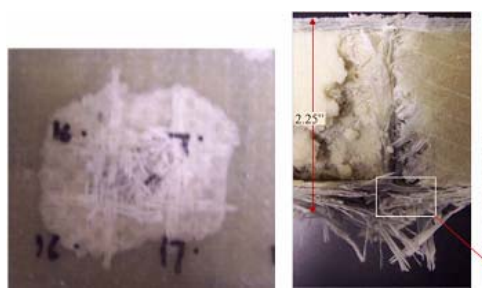

(a)
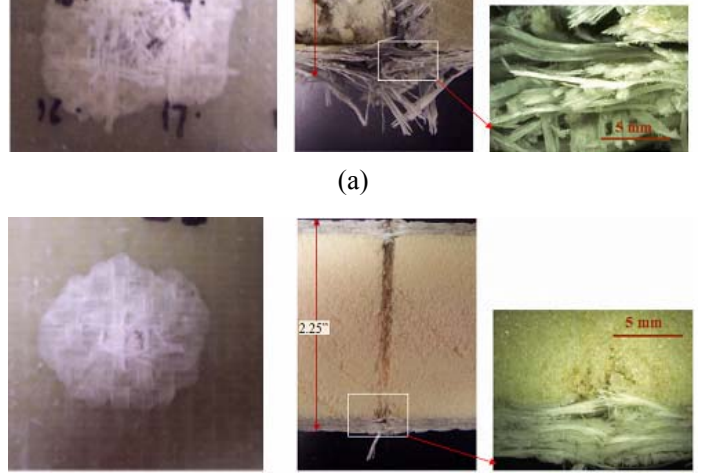

(b)
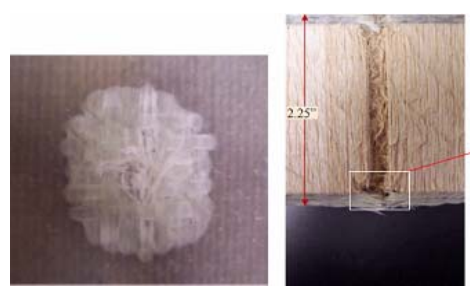

(c)
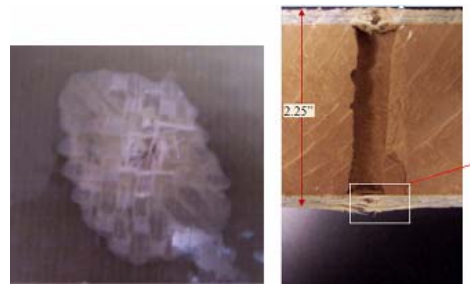

(d)
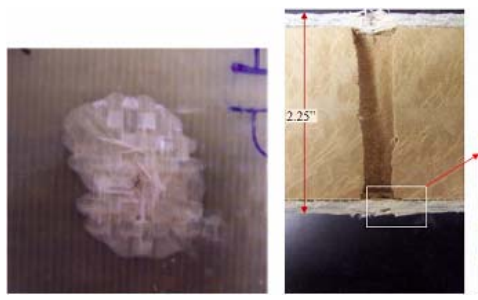

(e)
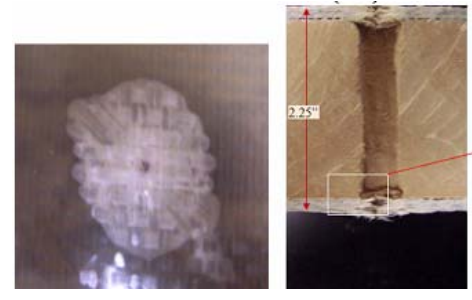

(f)
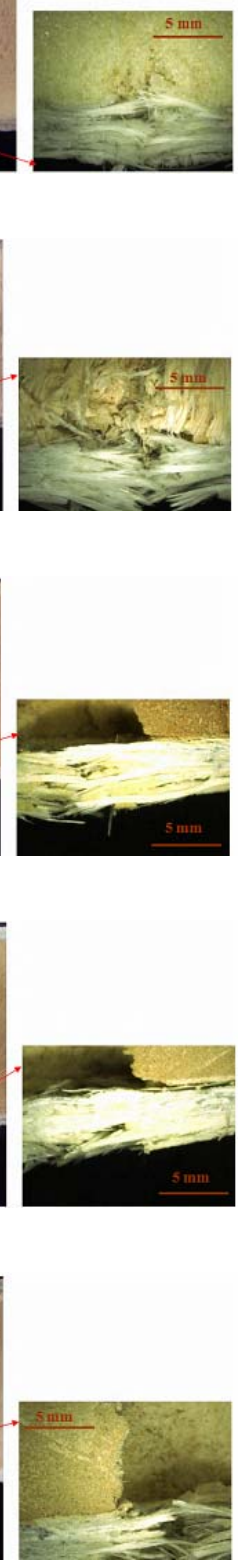

Figure 3. Sandwich composites made with five-ply E-glass face sheets and light-weight cores after ballistic impact (a) E-glass/Tycor impacted web-intersection; (b) E-glass/PVC; (c) E-glass/Balsa; (d) E-glass/EcoCore 0.0 wt. pct.; (e) Eglass/EcoCore 4.5 wt. pct. JM3 and (f) E-glass/Eco-Core 4.5 wt. pct. OC2. 


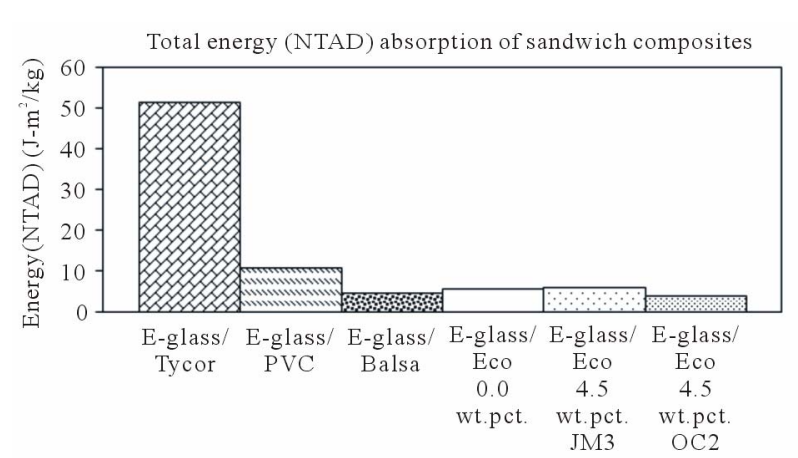

Figure 4. Energy absorption of sandwich composites in ballistic tests.

noted that Shot ID 4 in Tycor $^{\circledR}$ foam core panel shows higher residual velocity as well as the back face of panel shows large opening of the fractured skin at the shot location, which indicates that the projectile momentum was partly transferred to the large but light weight particle of foam which moved faster than the bullet during exit. The proof chronograph captured the higher velocity of the particle and not that of the projectile. Under these circumstances, the proof chronograph was triggered by the particle velocity which was higher than the projectile, causing erroneous results.

In low velocity punch-shear tests, the radial growth of damage in brominated 510A-40 vinyl ester nanoparticle reinforced composite panels; centering impact point was less for pure vinyl ester than its nanocomposites (Figure 5). Nanoclay reinforced composites were damaged equally on both faces, whereas graphite platelet reinforced composites showed more damage on the rear than impact side. In some cases of graphite platelet reinforced nanocomposites, fracture propagated very less on impact side. Penetration of plunger through the specimen required some more load due to the shearing friction between plunger wall and the inner surface of the punch through hole, which resulted in additional energy absorption.

Post-test views (Figure 6) of laminated woven fabric composite face sheets showed that radial growth of delamination was less for the E-glass/vinyl ester face sheet than HP-glass/vinyl ester face sheet and occurred on reverse side for both. Due to opacity of E-glass/xGnP-vinyl ester and T-700 Carbon/vinyl ester face sheets, the occurrence of delamination was not visible. In case of T-700 Carbon/vinyl ester face sheets, carbon fiber strands were peeled off partially from back side. The shredded fibers due to plunger penetration were clogged inside the puncture hole.

The visual inspection (Figure 7) of sandwich composites made with five-ply E-glass face sheets and lightweight cores showed that the radial growth of delamination is least in tougher core, and more in case of softer cores. E-glass/Tycor sandwich shows three different

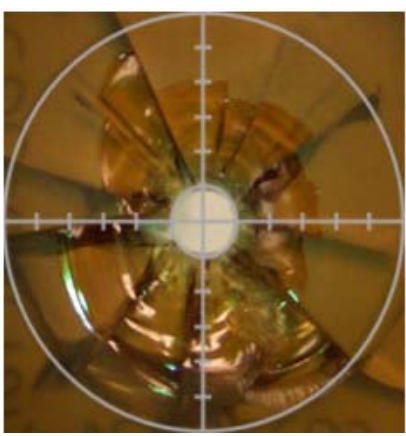

(a)

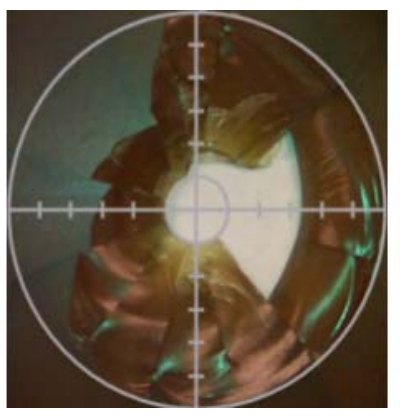

(b)

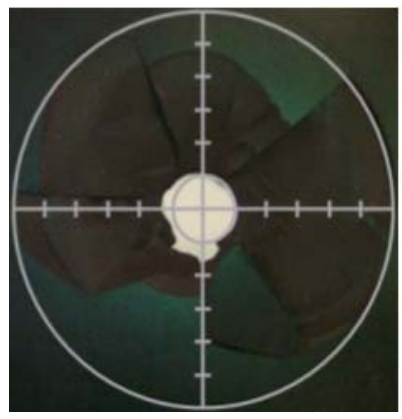

(d)

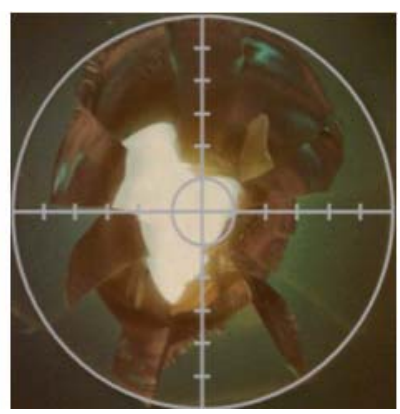

(c)

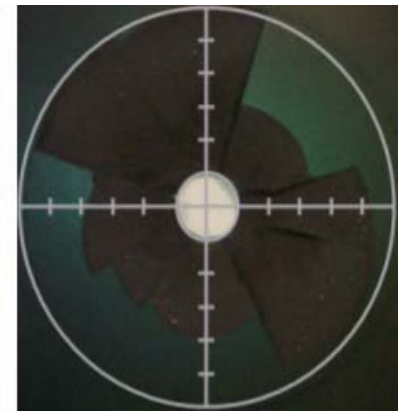

(e)
Figure 5. Back face fracture surfaces of brominated 510A40 vinyl ester nanoparticle reinforced composite panels after drop weight punch-shear testing. (a) Pure vinyl ester; (b) 1.25 wt. pct. nanoclay; (c) 2.5 wt. pct. nanoclay; (d) 1.25 wt. pct. graphite; (e) 2.5 wt. pct. Graphite.

modes of failure due to impact at web-intersection, webline and direct foam zones respectively. It can be observed that the softest foam-zone showed maximum delamination whereas the web-intersection allowed least delamination. Fly-ash based Eco-Core ${ }^{\circledR}$ is the toughest but also has highest density among all. It showed less delamination as well as less depth of penetration. PVC and Balsa cores showed average performance with respect to delamination and puncture.

Tortuosity of the fracture surface contributes to overall energy absorption during fracture propagation [11]. For brittle materials, Griffith criterion suggests that the energy absorbed by the crack growth is proportional to the new surface formed due to crack propagation [12], i.e., 


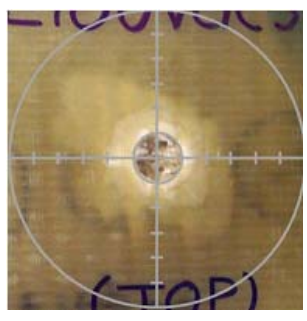

(a)

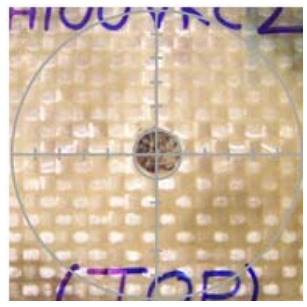

(c)

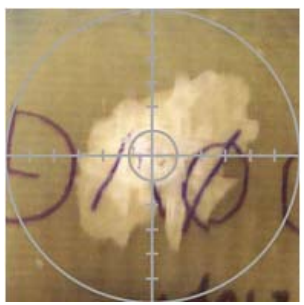

(a)

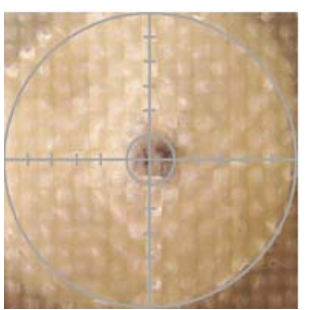

(c)

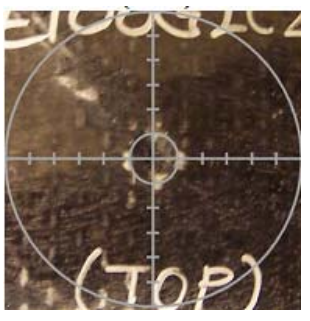

(b)

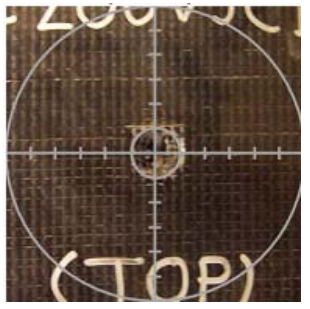

(d)

(A)

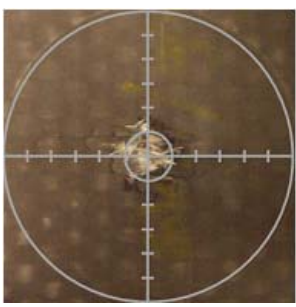

(b)

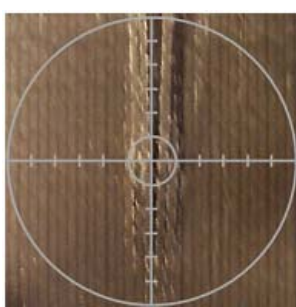

(d)
(B)

Figure 6. Laminated woven fabric composite face sheets after punch-shear tests [(A) impact side and (B) reverse side]. (a) E-glass; (b) E-glass/xGnP-15; (c) HP-glass; (d) T-700 carbon.

$$
E=\int P \mathrm{~d} x \approx W=2 \gamma a
$$

where, $\gamma=$ specific surface energy (depends on molecular bonding of materials), $a=$ fracture surface area. This surface energy $(W)$ contributes significantly to overall energy $(E)$ absorption.

In this research, the fracture surface area and the fracture surface roughness of post-test nano-reinforced specimens were estimated using a Keyence VHX-600E digital microscope [13] with a view port of $228.8 \mu \mathrm{m} \times$ $305.0 \mu \mathrm{m}$. The fine depth composition function of this
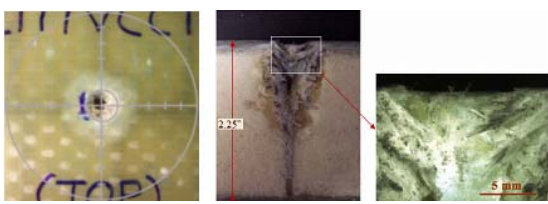

(a1)
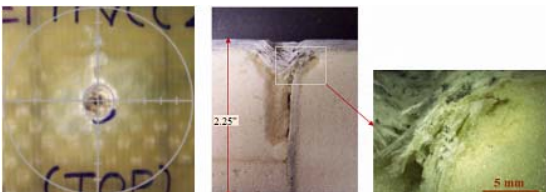

(a2)
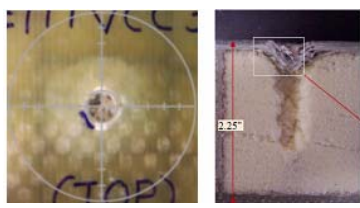

(a3)
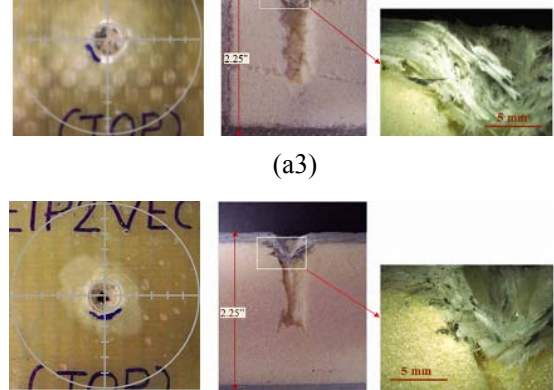

(b)
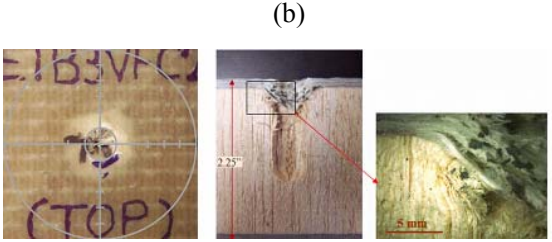

(c)
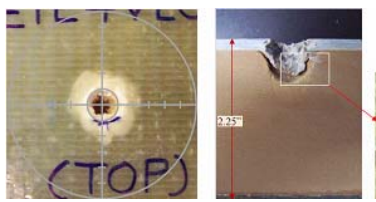

(d)
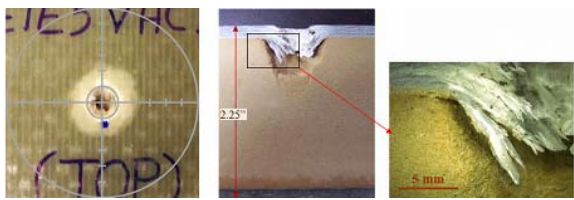

(e)
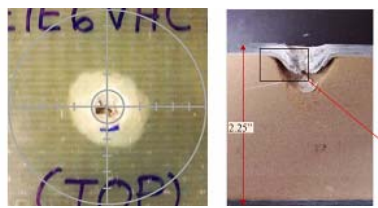

(f)
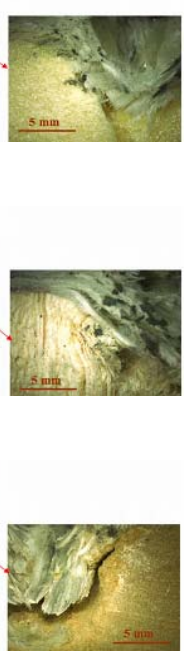

\section{.}


microscope system captured multiple images that focused on $70 \times 10^{3} \mu \mathrm{m}^{2}$ areas with $20 \mu \mathrm{m}$ increments of height for focul point and composed them into single 1000 times magnified 3D image. It created the 3-D data points of the fractured surface included in the observation area. These 3-D data points mapped the actual topography of fracture surface and estimated the tortuous surface area of crack propagation under the view port [14]. The longitudinal elevation $(z(x))$ of the surface topography was used to plot fracture surface profile $(L)$ [15] and estimated the fracture surface roughness using Equation (3).

$$
R_{a}=\frac{1}{L} \int_{0}^{L}|z(x)| \mathrm{d} x
$$

Surface area and roughness were estimated at 5 different locations on the back face of the post impacted specimen. The average data was considered statistically reasonable for fracture analysis of the nanocomposite specimens.

Pure vinyl ester showed the smoothest fracture surface with an average $3.6 \mu \mathrm{m}$ roughness and least $85.98 \times 10^{3}$ $\mu \mathrm{m}^{2}$ surface area. Nanoclay reinforcement increased the roughness a little more [9.2 $\mu \mathrm{m}$ and $11.2 \mu \mathrm{m}$ ]. Inclusion of graphite platelet reinforcement showed very rough fracture surface. Reinforcement with $2.5 \mathrm{wt}$. pct. graphite platelet has $29.6 \mu \mathrm{m}$ surface roughness with $143.71 \times 10^{3}$ $\mu \mathrm{m}^{2}$ fracture surface area. Large data scatter showed the heterogeneity of the fracture surface and the structure which is considered inherent to composites.

The Dynatup impulse data acquisition software provided instantaneous impact point displacement and applied load data. The load versus deflection data were plotted up to failure point for each tested sample. Corresponding cumulative energy absorption data were generated using approximate integration method (trapezoidal rule) (Equation (4)) [16].

$$
E=\int_{x_{i-1}}^{x_{i+1}} P(x) \mathrm{d} x \approx \frac{\Delta x}{2}\left[P\left(x_{i-1}\right)+2 P(x)+P\left(x_{i+1}\right)\right]
$$

where, $P=$ instantaneous applied load and $\Delta x=$ increment of material deformation.

Load versus deflection plot showed two distinct phases of failure propagation for complete puncture $[2,14]$. These two phases are damage initiation, the phase up to the peak load and puncture propagation, the phase of rapid load reduction after peak load. The total energy absorption was calculated as the sum of the energy absorbed for damage initiation and puncture propagation phases up to complete failure of the specimen. The total energy absorptions are normalized to areal density (NTAD) and shown in the form of bar charts to investigate the punch shear response of vinyl ester nanocomposites, laminated face sheets and sandwich composites under low velocity impact.

Pure vinyl ester and nanoclay reinforced vinyl ester showed stiff but linear load-deflection response at damage initiation stage. A little change of slope explained fracture initiations and plastic flow. Graphite platelet reinforced vinyl ester had distinctive multi-peak load fluctuations at this phase. This response showed large fracture generation at the rear side of the specimen. Energy absorption was carried out mainly at this phase. Vinyl ester nanocomposite panels showed sharp and smooth load-reduction. Comparatively harder and brittle graphite platelet reinforced nanocomposites absorbed less energy in puncture propagation phase. Puncture propagation phase absorbed less energy due to short duration and material fragmentation occurred severely with some hinging effects (Figure 8(a)). Nanoparticle reinforced vinyl ester panels showed more than $10 \%$ improvement in impact energy absorption with the addition of 2.5 wt. pct. graphite platelets to pure vinyl ester. However, the nanoclay and $1.25 \mathrm{wt}$. pct. graphite platelet reinforcements showed a detrimental effect (Figure 8(b)). Fracture surface area and respective fracture surface

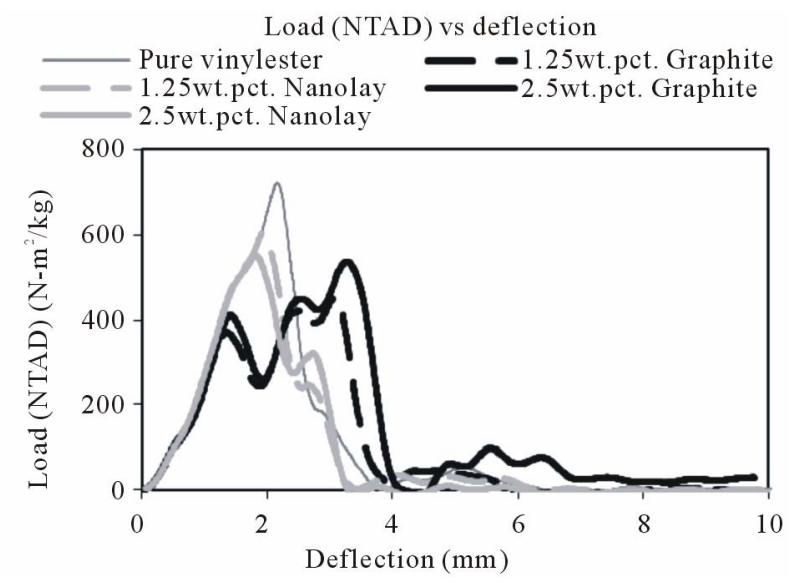

(a)

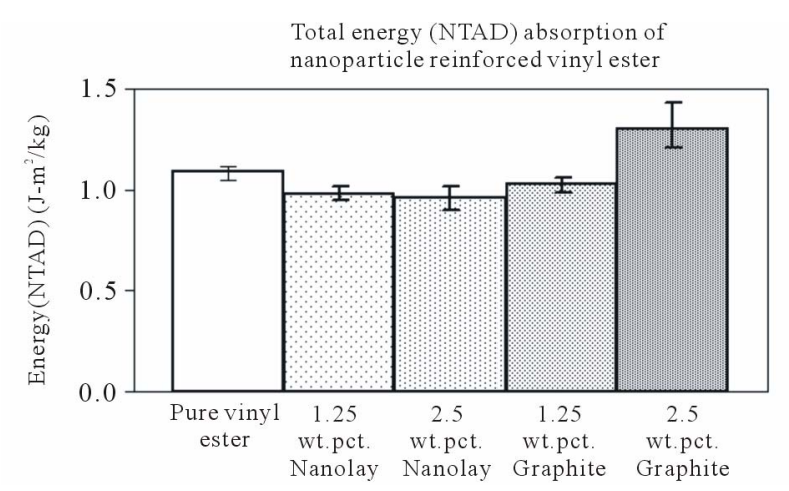

(b)

Figure 8. (a) Load (NTAD)-deflection response, and (b) Total energy (NTAD) absorbed for punch-shear test of vinyl ester nanocomposites. 
roughness (Figure 9) show their contribution to total energy absorption. Maximum fracture surface area and surface roughness for 2.5 wt. pct. graphite reinforced nanocomposite contributed to highest energy absorption. For rest of nano-reinforcement, the correlation between fracture surface roughness/area and the total energy absorption is however not that good.

All laminated face sheets showed a smooth elastic deformation with close initial stiffness. NTAD result for T-700 carbon fabric face sheet showed the highest stiffness in later stage than that of the other configurations. HP-glass/vinyl ester face sheet sustained maximum peak load among all. E-glass/vinyl ester and T-700 Carbon/vinyl ester face sheets took more or less same amount of load before puncture. E-glass/xGnP-vinyl ester composite took least load in this phase. However, this face sheet fairly deflected during the damage initiation phase and hence absorbed maximum energy up to peak load same as HP-glass/vinyl ester face sheet; whereas T-700 Carbon/vinyl ester absorbed least energy. Some prominent hinging effects of attached fiber fragments with the surface of the plunger are observed in case of all laminated face sheets. Only E-glass/xGnP-vinyl ester composite showed comparatively smooth puncture propagation. HP-glass/vinyl ester composite face sheet pro

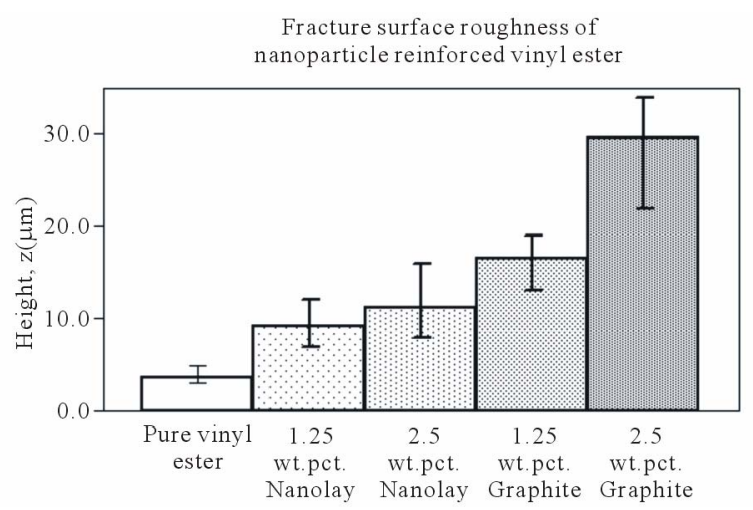

(a)

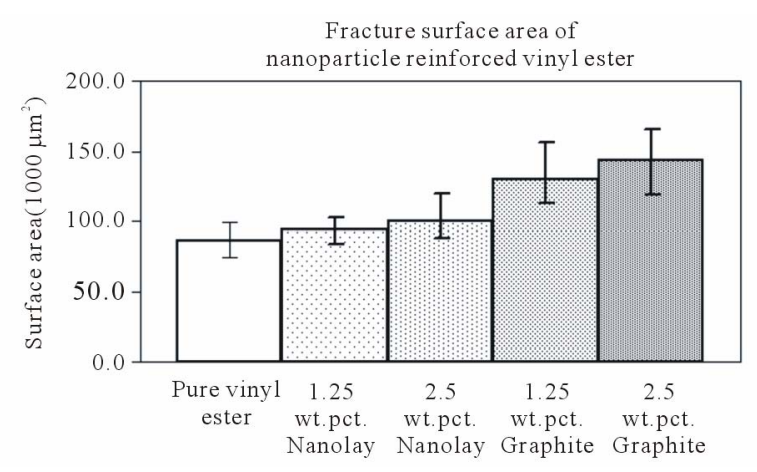

(b)

Figure 9. (a) Fracture surface roughnesses and (b) Fracture surface areas of vinyl ester nanocomposites. vided lot of resistance after peak load and continued to cause delamination. Hence the load-deflection plot shows a distinctive wavy plateau region at peak load (Figure 10(a)). Laminated woven fabric composite face sheets showed that the addition of graphite platelets in vinyl ester matrix absorbed approx. $10 \%$ more energy than reference E-glass face sheet; whereas the FOE treated T-700 carbon fabric displayed lowest energy absorption. Maximum improvement in energy absorption (about $40 \%)$ was observed with Owens Corning HP ShieldStrand ${ }^{\circledR}$ glass fabric face sheets compared to the E-glass/ vinyl ester (Figure 10(b)).

The sandwich composites showed (Figures 11(a)) five clear peaks indicating failure of each woven fiber lamina on the impact side of face sheets up to peak load. PVC sandwich fails at minimum peak load. All other sandwiches took approximately same amount of load at this phase. In case of sandwich composites, load reduction was very less and slow. Plunger could not penetrate much in the 2.25 " thick sandwich specimens. Lot of hinges demonstrated uneven resistance due to ripped

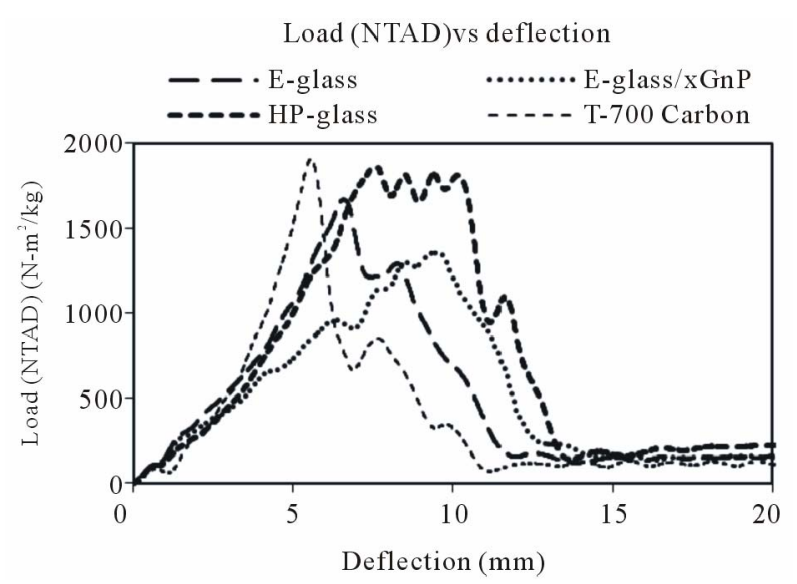

(a)

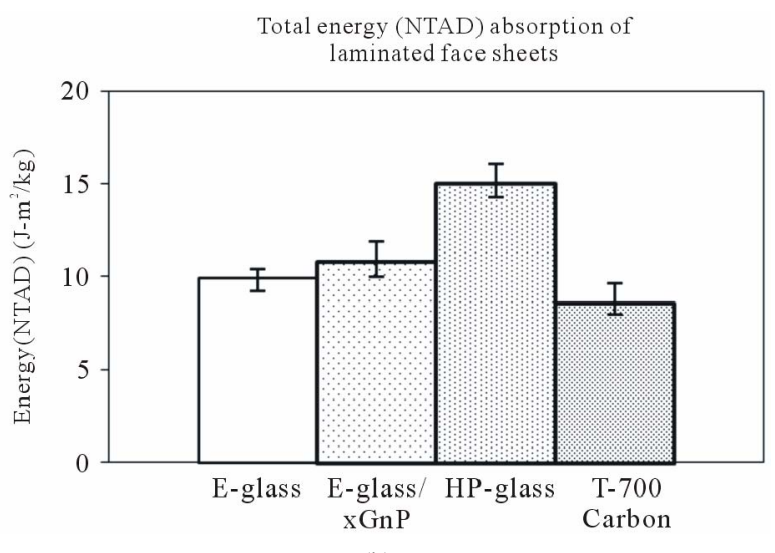

(b)

Figure 10. (a) Load (NTAD)-deflection response, and (b) Total energy (NTAD) absorbed for punch-shear test of laminated face sheets. 


\section{Load (NTAD)vs deflection}

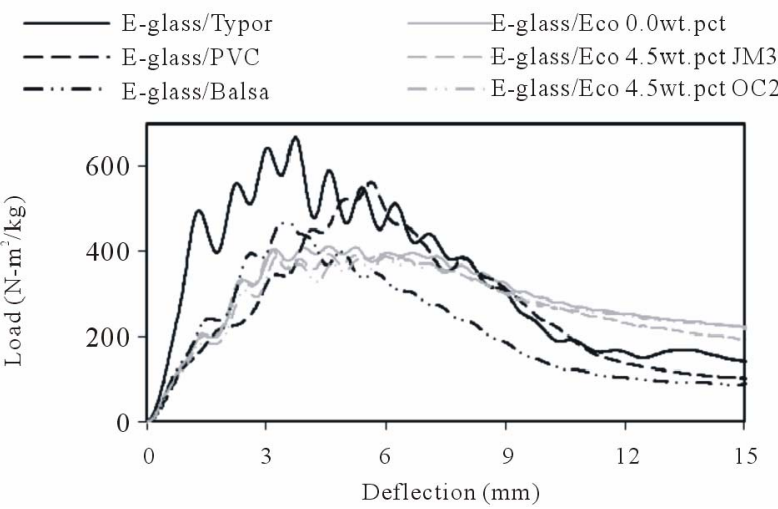

(a)

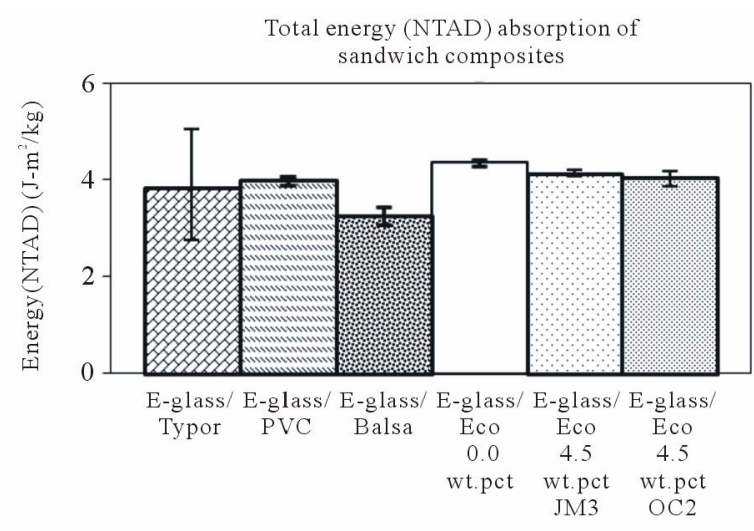

(b)

Figure 11. (a) Load (NTAD)-deflection response, and (b) Total energy (NTAD) absorbed for punch-shear test of sandwich composites.

fiber and core materials which influenced significant energy absorption after peak load. Sandwich composites made with five-ply E-glass face sheets and light-weight cores showed that PVC and Balsa sandwiches absorbed more or less same energy. The Tycor ${ }^{\circledR}$ sandwich composite has glass fiber webs embedded in the foam core. The punch-shear energy absorption at the intersection of the webs was observed to be double of that at foam-region.

The response at web line was an average of that at other two locations. Spatial non-uniformity of the core resulted in large data scatter, with the average response of Tycor ${ }^{\circledR}$ sandwich composite similar to that of PVC foam and balsa wood sandwich composites. The higher density of Eco-Core ${ }^{\circledR}$ core provided significant resistance to plunger penetration during impact which resulted in higher energy absorption than other sandwich composites made with light-weight and softer core. The energy absorption normalized to areal density (NTAD) showed (Figure 11(b)) Eco-Core ${ }^{\circledR}$ sandwich composite having $10 \%$ better energy absorption among all, though the chopped glass fiber reinforcement in core did not contribute much in energy absorption improvement. Tycor ${ }^{\mathbb{B}}$ sandwich composite absorbed maximum energy only when plunger impacted at web intersection region.

\section{Conclusions}

Sandwich composites were tested under both low velocity punch-shear and high velocity ballistic loading. On impact at the web-reinforcement intersection region, Tycor $^{\circledR}$ sandwich absorbed significant amount of energy in both punch-shear and ballistic tests. However considering overall average performance of the samples, EcoCore ${ }^{\circledR}$ performed the best in energy absorption during punch-shear tests, but performed poorly in ballistic tests.

High velocity impact loading by a small projectile was observed to be more detrimental to the integrity of a composite structure than low velocity drop weight punchshear impact loading. Intra-lamina delamination, fiber breakage, face sheet-core separation were more visible in case of high velocity ballistic impact than low velocity punch-shear. The larger impact plunger with lower impact energy damaged the core system lesser than the high velocity projectile. Ballistic penetration occurred in EcoCore $^{\circledR}$ sandwich by dislodging brittle core fragments and creating a through cylindrical hole. Punch-shear testplunger could not even penetrate more than 0.6 " in 2.25 " thick Eco-Core ${ }^{\circledR}$ sandwich composites.

Multi-site high velocity projectile impact testing was conducted on sandwich panels of E-glass/vinyl ester skins with different core materials. The residual velocity of the projectile was highly influenced by the energy absorbability of core materials. Sequential impact caused an increase in delamination damage along with complete core perforation and fiber breakage. The visual analysis of post-impact composite panels concludes that projectiles passed through the panel thickness, tearing and delaminating the E-glass/Vinyl ester skin and penetrating core materials. The delamination and puncture of the skin due to penetration occupied more area at the back face with respect to the front face due to high deceleration rate. Less deceleration of the projectiles was observed for sandwich specimens with balsa and PVC and Eco-Core ${ }^{\circledR}$ cores. Minimally damaged regions indicate lower energy absorption capacity. These unreinforced cores offer less shear resistance at high velocities, while energy absorption enhances with core reinforcement. Tycor $^{\circledR}$ core sandwich panel absorbed maximum kinetic energy, whereas other sandwich panels performed worse in energy absorption. PVC foam core sandwich panel absorbed little bit more energy than other sandwich panel. Eco-Core ${ }^{\circledR}$ sandwich panels could not absorb much kinetic energy of the projectile.

Low velocity punch-shear test results show more than 
$10 \%$ improvement in impact energy absorption with addition of 2.5 wt. pct. graphite platelets to pure vinyl ester, whereas addition of nanoclay and $1.25 \mathrm{wt}$. pct. graphite platelet reinforcements showed detrimental effect. Owens Corning HP ShieldStrand ${ }^{\circledR}$ glass fabric face sheets showed maximum improvement in energy absorption (about 40\%) compared to the E-glass/vinyl ester. High areal density of Eco-Core ${ }^{\circledR}$ sandwich composites showed very high energy absorption among all of the sandwich specimens. The even assessment of energy absorption among these panels have been carried out by normalizing their load taking capacity and energy absorptions to their respective areal densities (NTAD). Eco-Core ${ }^{\circledR}$ sandwiches performed the best in energy absorption; with chopped fiber reinforcements not providing any improvement. Normalized test results showed that Tycor ${ }^{\circledR}$ sandwich composite absorbed higher energy at the web intersection regions.

\section{Acknowledgements}

This investigation was supported by ONR Grant No 001407-1-1010, Office of Naval Research, Solid Mechanics Program (Dr. Yapa D. S. Rajapakse, Program Manager). The nanoclay and graphite platelet vinyl ester composite panels were manufactured by Dr. Larry Drzal's group at Michigan State University. HP ShieldStrand ${ }^{\circledR}$ glass fabric was supplied by Owens Corning. Composite face sheets and sandwich panels were manufactured and ballistic tests were performed by Dr. Uday Vaidya's group at University of Alabama-Birmingham. Tycor ${ }^{\circledR}$ cores were supplied by WebCore Technologies, Miamisburg, $\mathrm{OH}$. Fly-ash based Eco-Core ${ }^{\circledR}$ cores were manufactured by Dr. Kunigal Shivakumar at North Carolina A \& T State University.

\section{REFERENCES}

[1] B. A. Gama and J. W. Gillespie Jr., "Punch Shear Based Penetration Model of Ballistic Impact of Thick-Section Composites," Composite Structures, Vol. 86, No. 4, 2008, pp. 356-369. doi:10.1016/j.compstruct.2007.11.001

[2] B. A. Gama, S. M. W. Islam, M. Rahman, J. W. Gillespie Jr., T. A. Bogetti, B. A. Cheeseman, C. Yen and C. P. R. Hoppel, "Punch Shear Behavior of Thick-Section Composites under Quasi-Static, Low Velocity, and Ballistic Impact Loading," SAMPE Journal, Vol. 41, No. 4, 2005, pp. 6-13.

[3] J. R. Xiao, B. A. Gama and J. W. Gillespie Jr., "Progressive Damage and Delamination in Plain Weave S-2 Glass/ SC-15 Composites under Quasi-Static Punch-Shear Load- ing," Composite Structures, Vol. 78, No. 2, 2007, pp. 182196. doi:10.1016/i.compstruct.2005.09.001

[4] M. Shaker, F. Ko and J. Song, "Comparison of the Low and High Velocity Impact Response of Kevlar Fiber-Reinforced Epoxy Composites," Journal of Composites Technology and Research (JCTR), Vol. 21, No. 4, 1999, pp. 224-229. doi:10.1520/CTR10985J

[5] M. V. Hosur, C. R. L. Murthy and T. S. Ramamurthy, "Low-Velocity Impact Response and Evaluation of Delamination Damage in CFRP Laminates," Noise Control and Acoustics Division, ASME, Vol. 24, 1997, pp. 203214.

[6] L. J. Deka, S. D. Bartus and U. K. Vaidya, "Multi-Site Impact Response of S2-Glass/Epoxy Composite Laminates," Composite Science and Technology, Vol. 69, No. 6, 2009, pp. 725-735. doi:10.1016/j.compscitech.2008.03.002

[7] J. E. Samuels and K. M. Higgins, "Ballistic Resistance of Personal Body Armor, NIJ Standard-0101.04," National Institute of Justice and National Institute of Standards and Technology, Gaithersburg, 2000.

[8] ASTM Standard D3763, "Standard Test Method for High Speed Puncture Properties of Plastics Using Load and Displacement Sensors," ASTM International, West Conshohocken, 2006.

[9] L. T. Drzal and H. Fukushima, "Expanded Graphite Products Produced Therefrom," US Patent No. 7550529, 2009.

[10] E. Wang, N. Gardner and A. Shukla, "The Blast Resistance of Sandwich Composites with Stepwise Graded Cores," International Journal of Solids and Structures, Vol. 46, No. 18-19, 2009, pp. 3492-3502.

[11] R. L. Smith, J. J. Mecholsky and S. W. Freiman, "Estimation of Fracture Energy from the Work of Fracture and Fracture Area: I. Stable Crack Growth," International Journal of Fracture, Vol. 156, No. 1, 2009, pp. 97-102. doi:10.1007/s10704-009-9350-7

[12] D. Broek, "Elementary Engineering Fracture Mechanics," Martinus Nijhoff Publishers, Leiden, 1982. doi:10.1007/978-94-011-9055-8

[13] Keyence Corporation, "User's Manual 96MOO189, Digital Microscope VHX-600E," Keyence Corporation, Elmwood Park, 2007.

[14] B. Pramanik, "Punch-Shear and Ballistic Energy Absorption Characteristics of Nano-Reinforced Panels, Laminated Face Sheets and Sandwich Composites," M.S. Thesis, University of Mississippi, Oxford, 2010.

[15] M. S. Lou, J. C. Chen and C. M. Li, "Surface Roughness Prediction Technique for CNC End-Milling," Industrial Technology, Vol. 15, No. 1, 1999, pp. 1-6.

[16] D. Hyde, "DPlot User Manual," HydeSoft Computing, LLC, Vicksburg, 2008. 